\title{
Teachers of Arts and Culture and the Continuing Professional Development
}

\author{
Oleh: \\ Sri Kristati \\ Guru SMP Negeri 3 Jumapolo Kabupaten Karanganyar \\ Alumni Pendidikan Seni Tari FBS UNY
}

\begin{abstract}
The teaching profession has consequences and it needs programmed and continuing guidance and development strategies to support the improvement of professionalism. Through Continuing Professional Development, teachers can maintain, improve, and develop knowledge and skills to implement learning processes professionally and optimally. Quality learning is expected to be capable of improving students' knowledge, skills, and attitudes. Continuing Professional Development from the aspect of professional development is expected to assure that every teacher can attain and fulfil the competency standard and acquire competencies in accordance with the professionalism level and can provide standard and quality services in learning in order for learners to be capable of developing themselves based on their potentials. From the aspect of career development, Continuing Professional Development can assure teachers in obtaining credit points that they need for their career levels, having opportunities to develop their professional careers based on their wishes, and developing their professional experiences based on their responsibilities.
\end{abstract}

Keywords: Continuing Professional Development, professionalism, teachers of Art and Culture 


\section{A. PENDAHULUAN}

Sesuai amanat UU Nomor 14 Tahun 2005 tentang Guru dan Dosen (UUGD), profesi guru harus dikembangkan sebagai profesi yang bermartabat, maka guru harus benar-benar mampu berupaya untuk selalu mengembangkan dan meningkatkan potensi dan kompetensinya. Dengan itu, fungsi, peran, dan kedudukannyadalam mewujudkan visi pendidikan, yaitu menciptakan insan Indonesia yang cerdas dan kompetitif, dapat tercapai.

Guru diharapkan mampu berpartisipasi dalam pembangunan nasional untuk mewujudkan insan Indonesia yang bertaqwa kepada Tuhan Yang Maha Esa, unggul dalam ilmu pengetahuan dan teknologi, memiliki jiwa estetis, etis, berbudi pekerti luhur, dan berkepribadian.Oleh karena itu, guru - apapun mata pelajaran yang diampunya -- berkewajiban untuk selalu berupaya meningkatkan dan mengembangkan potensi dan kompetensinya demi tercapainya tujuan pendidikan nasional.

Guru harus selalu peka terhadap setiap perubahan yang terjadi dilingkup pendidikan, berkaitan dengan kebijakan Pemerintah dalam hal penerapan dan revisi kurikulum, maupun dalam hal inovasi strategi model/metode pembelajaran. Dengan demikian, guru dapat terhindar dari ketertinggalan demi kemajuan pendidikan dan peningkatan profesionalitasnya.

Konsekuensi jabatan guru sebagai profesi memerlukan strategi pembinaan dan pengembangan secara terprogram dan berkelanjutanguna mendukung peningkatan profesionalitas guru. Pemerintah c.q. Menteri Pendayagunaan Aparatur Negara dan Reformasi Birokrasi RI telah menetapkan Peraturan Menteri Pendayagunaan Aparatur Negara dan Reformasi Birokrasi Nomor 16 Tahun 2009tentang Jabatan Fungsional Guru dan Angka Kreditnya. Salah satu aspek angka kredit yang dipersyaratkan untuk dipenuhi dapat dicapai melalui pelaksanaan kegiatan Pengembangan Keprofesian Berkelanjutan (PKB). PKB itu 
sendiri merupakan suatu kegiatan yang dirancang untuk mewujudkan terbentuknya guru yang profesional.

Pada kenyataannya, sikap guru terhadap kegiatan PKB,terutama dalam aspek Publikasi Ilmiah dan Karya Inovatifmasih belum menggembirakan. Tampaknya ada berbagai alasan mengapa guru-guru cenderung pasif, diantaranya masa kerja yang tinggal beberapa tahun, kenaikan pangkat masih lama, belum ada tuntutanyang mendesak, belum punya ide, belum menemukan masalah, dan seterusnya. Semua itu mereka sampaikan demi menghindari kegiatan PKB tersebut. Kalau saja sikap para guru seperti ini terus, pertanyaannya adalah akankah profesionalisme guru dapat meningkat dan akankah tujuan pendidikan nasional tercapai.Permasalahan-permasalahan seperti itu telah menemukan urgensi dan relevansinya untuk segera dicarikan pemecahan atau solusinya, dan segera disikapi secara arif oleh para guru.

\section{B. PEMBAHASAN}

\section{Konsep PKB}

PKB berdasarkan Peraturan Menteri Negara Pendayagunaan Aparatur Negara dan Reformasi Birokrasi Nomor 16 Tahun 2009 adalah pengembangan kompetensi guru yang dilaksanakan sesuai kebutuhan, bertahap, berkelanjutan untuk meningkatkan profesionalitas. PKB dapat dilaksanakan melalui berbagai kegiatan yang meliputi: Pengembangan Diri (PD), Publikasi Ilmiah (PI), dan Karya Inovatif (KI).

a. PD dapat dilaksanakan melalui: (1) Diklat Fungsional yang bertujuan meningkatkan keprofesian guru dalam kurun waktu tertentu, bisa berupa kursus, pelatihan, penataran atau diklat, (2) mengikuti Kegiatan Kolektif Guru, misalnya melalui organisasi MGMP dilaksanakan kegiatan: seminar, lokakarya (IHT), sebagai peserta maupun pembahas atau pemakalah.

b. PI dilaksanakan melalui berbagai kegiatan yang bisa dilakukan oleh guru berdasarkan kompetensinya misalnya: presentasi pada forum ilmiah, publiksai hasil penelitian atau gagasan inovatif pada bidang pendidikan formal, publikasi 
buku teks pelajaran, buku pengayaan/buku pedoman guru. Wujudnya dapat berupa: (1) laporan hasil penelitian, (2) tinjauan ilmiah, (3) tulisan ilmiah populer, dan(4) artikel ilmiah.

c. KI dilakukan melalui kegiatan: (1) menemukan teknologi tepat guna, (2) menemukan/menciptakan karya seni, (3) membuat/memodifikasi alat pelajaran/peraga/praktikum, (4) mengikuti pengembangan penyusunan standar, pedoman,soal dan sejenisnya.

\section{Tujuan PKB}

PKB dilaksanakan agar guru dapat memelihara, meningkatkan, dan memperluas pengetahuan dan keterampilannya untuk melaksanakan proses pembelajaran secara profesional dan optimal. Pembelajaran yang berkualitas tersebut diharapkan mampu meningkatkan pengetahuan, keterampilan dan sikap peserta didik.

Secara umum, pelaksanaan PKB bertujuan untuk meningkatkan kualitas layanan pendidikan disekolah/madrasah dalam rangka meningkatkan mutu pendidikan. Adapun secara khusus tujuan dari PKB sebagai berikut.

a. Meningkatkan kompetensi guru untuk mencapai standar kompetensi yang ditetapkan dalam peraturan perundang-undangan yang berlaku;

b. Memutkhirkan kompetensi guru untuk memenuhi kebutuhan gurudalam perkembangan ilmu dan pengetahuan, teknologi, dan seni untuk memfasilitasi proses pembelajaran peserta didik;

c. Meningkatkan komitmen guru dalam melaksanakan tugas pokok dan fungsinya sebagai tenaga profesional;

d. Menumbuhkan rasa cinta dan bangga sebagai penyandang profesi guru;

e. Meningkatkan citra, harkat, dan martabat profesi guru di masyarakat; dan

f. Menunjang pengembangan karir guru.

\section{Manfaat PKB}


Manfaat pelaksanaan PKB dapat dilihat dari dua sisi, yaitu dari sisi pengembangan profesionalisme dan sisi pengembangan karir guru. Dari sisi pengembangan profesionalisme, pelaksanaan PKB diharapkan dapat menjamin: 1) setiap guru akan dapat mencapai dan memenuhi standar kompetensi, 2) setiap peserta didik mendapatkan pelayanan yang standar dan berkualitas dalam pendidikan, sehingga dapat mengembangkan diri sesuai potensinya, 3) setiap guru memiliki penguasaan kompetensi yang sesuai dengan jenjang profesionalnya.

Di sisi lain, pengembangan karir diharapkan dapat menjamin guru dalam: 1) memperoleh nilai angka kredit yang dibutuhkan untuk jenjang karirnya, 2) memiliki kesempatan untuk mengembangkan karir profesi yang sesuai dengan keinginannya, 3) mengembangkan pengalaman profesionalismenya sesuai dengan tanggungjawabnya.

Seorang guru tidak dapat mengajar apabila dia tidak memiliki pengetahuan dan keterampilan. Seperti yang diamanatkan dalam Permen Diknas No. 16/2007 tentang Standar Kualifikasi dan Kompetensi Guru, bahwa guru harus memenuhi 4 standar kompetensi (Pedagogi,Profesional, Kepribadian, dan Sosial) yang diwujudkan dalam pelaksanaan 3 tugas utama: perencanaan, pelaksanaan, dan penilaian.

Standar Kompetensi Guru Mata Pelajaran/Guru Kelas meliputi:

a. Kompetensi Pedagogi:

1) Mengenal karakteristik anak didik;

2) Menguasai teori belajar dan prinsip-prinsip pembelajaran yang mendidik;

3) Pengembangan kurikulum;

4) Kegiatan pembelajaran yang mendidik;

5) Memahami dan mengembangkan potensi;

6) Komunikasi dengan peserta didik; dan

7) Penilaiaan dan evaluasi.

b. Kompetensi Kepribadian: 
1) Bertindak sesuai dengan norma agama,hukum, sosial, dan kebudayaan nasional Indonesia;

2) Menunjukkan pribadi yang dewasa dan teladan; dan

3) Etos kerja, tanggungjawab yang tinggi, rasa bangga sebagai guru.

c. Kompetensi Sosial:

1) Bersikap inklusif, bertindak objektif, serta tidak deskriminatif;

2) Komunikasi dengan semua warga dilingkungan pendidikan, orangtua peserta didik, dan masyarakat.

d. Kompetensi Profesional:

1) Penguasaan materi struktur konsep dan pola pikir keilmuan yang mendukung mata pelajaran yang diampu;

2) Mengembangkan keprofesian melalui tindakan reflektif.

\section{Guru Seni Budaya Memandang PKB}

PelaksanaanPKB disesuaikan dengan kebutuhan masing-masing guru. Pelaksanaannyaitu dapat dilakukan secara individu maupunsecara kelompok/kolektif melalui forum Musyawarah Guru Mata Pelajaran (MGMP). Kegiatan yang dapat dilakukan secara kolektif berupa kegiatan PD, misalnya diklat,pelatihan,kursus, dan seminar. Sedangkan kegiatan PI dan KI dapat dilaksanakan secara individu atau kelompok.

Untuk kegiatan PD, rata-rata bagi guru tidak menjadi masalah karena biasanya mereka dapat melaksanakannya secara kolektif. Sebagai contoh, keikutsertaan dalam kegiatan atauforum-forumilmiah, misalnya seminar atau lokakarya (IHT). Mereka bisa mengikuti kegiatan tersebut tanpa harus aktif, artinya mereka hanya terlibat sebatas sebagai peserta dan itupun sudah diakui meskipun poin(angka kredit)-nya hanya kecil/sedikit. Tetapi, untuk kegiatan PI dan KI, tampaknya masih menjadi hal yang mereka anggap 'layak untuk dihindari'. 
Beberapa waktu yang lalu adaisu bahwa kenaikan pangkat/jabatanuntuk Pegawai Negeri Sipil (PNS) akan dilaksanakan secara otomatis tanpa melalui mekanisme pengajuan/pengusulan. Banyak guru menyambutnya dengan gembiraria dansuka-citatanpa mencobamemahamimakna dan maksud yang sebenarnya terkandung padaisutadi.Kegembiraan mereka itudilatarbelakangiatas pemikiranbahwa mereka akanbisa terusnaik pangkat tanpa harus bersusah-susah memeras kemampuan membuattulisan ilmiah atau karya inovatif khususnya, dan melaksanakan kegiatan PKB secara umum. Mereka cukup menunggu waktukenaikan pangkat/jabatanyang dengan sendirinya akan datang secara otomatis dan secara tiba-tiba. Sikap dan pemikiran seperti itu sungguh mengenakkan dan dapat meninabobokan para guru, yang ujung-ujungnya mereka terlena dalam kepasifan.

Bayangan-bayangan yang mengenakkan seperti itu tadi akhirnya terjawab dengan pasti bahwa harapan para guru tadi keliru. Dalam sebuah wawancara di TVRI pada 9 Juni 2015 Kepala Badan Kepegawaian Nasional (BKN),Dr.Ir. Bima Haria Wibisana, MSIS, menegaskan bahwa kenaikan pangkat/jabatan secara otomatis itudiperuntukkan PNS yang masuk dalam jajaran struktural. Sedangkan untukPNS dalam jajaran fungsional, kenaikan pangkat/jabatannya tetap berdasarkan pencapaian angka kredit.

Dari penjelasan diatasdapat ditangkap bahwa bagi guru (penyandang jabatan fungsional) tetap mempunyai keharusan melaksanakan kegiatan PKB, yang poin dan porsinya sudah ditetapkan. Hal itu mengingat bahwa dalam setiap jenjang kenaikan pangkat/jabatan sudah ada ketetapan angka kreditnya, seperti yang diamanatkan dalam Permenneg PAN dan RB Nomor 16 Tahun 2009 tentang Jabatan Fungsional Guru dan Angka Kreditnya. 
Tabel 1.JenjangJabatanFungsional Guru

JENJANG JABATAN FUNGSIONAL GURU

(Permenneg PAN \& RB No.16/2009, pasal 17)

\begin{tabular}{|c|c|c|c|c|c|}
\hline \multirow{3}{*}{$\begin{array}{c}\text { Guru } \\
\text { Pertama }\end{array}$} & Penata Muda IIIa & 100 & & & $A K$ \\
\hline & & & 50 & $3 \mathrm{pd}, 0 \mathrm{pi} / \mathrm{n}$ & 5 \\
\hline & Penata Muda Tingkat I, IIIb & 150 & 50 & $3 \mathrm{nd} / 4 \mathrm{ni} / \mathrm{n}$ & 5 \\
\hline \multirow{2}{*}{$\begin{array}{l}\text { Guru } \\
\text { Muda }\end{array}$} & Penata, Illc & 200 & \multirow{2}{*}{100} & \multirow{2}{*}{$3 \mathrm{pd}, 6 \mathrm{pi} / \mathrm{n}$} & \multirow{2}{*}{10} \\
\hline & Penata Tinakat I. Illd & 300 & & & \\
\hline \multirow{4}{*}{$\begin{array}{c}\text { Guru } \\
\text { Madya }\end{array}$} & & & 100 & $4 \mathrm{pd}, 8 \mathrm{pi} / \mathrm{n}$ & 10 \\
\hline & Pembina, IVa & 400 & 150 & $4 \mathrm{pd}, 12 \mathrm{pi} / \mathrm{n}$ & 15 \\
\hline & Pembina Tingkat I, IVb & 550 & 150 & $4 \mathrm{pd}, 12 \mathrm{pi} / \mathrm{n}$ & 15 \\
\hline & Pembina Utama Muda, IVc & 700 & 150 & $5 \mathrm{pd}, 14 \mathrm{pi} / \mathrm{n}$ & 15 \\
\hline \multirow{2}{*}{$\begin{array}{l}\text { Guru } \\
\text { Utama }\end{array}$} & Pembina Utama Madya, IVd & 850 & \multirow{2}{*}{200} & \multirow{2}{*}{$5 \mathrm{pd}, 20 \mathrm{pi} / \mathrm{n}$} & \multirow{2}{*}{20} \\
\hline & Pembina Utama, IVe & 1050 & & & \\
\hline
\end{tabular}

Kebutuhan Angka Kredit Komulatif (AKK) , PKB (AKPKB), dan Unsur Penunjang (AKP) untuk kenaikan pangkatedandjabatan

Berdasar tabel diatas kebutuhan angka kredit dari unsur PKB untuk kenaikan pangkat/jabatan satu tingkat lebih tinggi dapat ditabelkansebagai berikut.

Tabel 2.Jabatan, Pangkat, Golongan Ruang, dan Persyaratan Angka Kreditnya

\begin{tabular}{|c|c|c|c|}
\hline Jabatan & Pangkat & $\begin{array}{c}\text { Gol./ } \\
\text { Ruang }\end{array}$ & Persyaratan Angka Kredit \\
\hline \multirow{2}{*}{$\begin{array}{l}\text { Guru } \\
\text { Pertama }\end{array}$} & Penata Muda & $\mathrm{III} / \mathrm{a}$ & 50; minimum 3 dari PD \\
\hline & $\begin{array}{l}\text { Penata Muda } \\
\text { Tingkat I }\end{array}$ & $\mathrm{III} / \mathrm{b}$ & $\begin{array}{l}\text { 50; minimum } 3 \text { dari } \mathrm{PD}, 4 \text { dari } \\
\mathrm{PI} / \mathrm{KI}\end{array}$ \\
\hline \multirow[t]{2}{*}{ Guru Muda } & Penata & $\mathrm{III} / \mathrm{c}$ & $\begin{array}{l}\text { 100; minimum } 3 \text { dari PD, } 6 \text { dari } \\
\text { PI/KI }\end{array}$ \\
\hline & Penata Tingkat I & $\mathrm{III} / \mathrm{d}$ & $\begin{array}{l}\text { 100; minimum } 4 \text { dari PD, } 8 \text { dari } \\
\text { PI/KI }\end{array}$ \\
\hline \multirow[t]{3}{*}{ Guru Madya } & Pembina & IV/a & $\begin{array}{l}\text { 150; minimum } 4 \text { dari PD, } 12 \text { dari } \\
\text { KI }\end{array}$ \\
\hline & $\begin{array}{l}\text { Pembina } \\
\text { Tingkat I }\end{array}$ & $\mathrm{IV} / \mathrm{b}$ & $\begin{array}{l}\text { 150; minimum } 4 \text { dari PD, } 12 \text { dari } \\
\text { PI/KI }\end{array}$ \\
\hline & Pembina Utama & $\mathrm{IV} / \mathrm{c}$ & 150; minimum 5 dari PD, !4 dari \\
\hline
\end{tabular}




\begin{tabular}{|l|l|l|l|}
\hline & Muda & & PI/KI \\
\hline Guru Utama & $\begin{array}{l}\text { Pembina Utama } \\
\text { Madya }\end{array}$ & IV/ d & $\begin{array}{l}\text { 200; minimum 5 dari PD, 20 dari } \\
\text { PI/KI }\end{array}$ \\
\cline { 2 - 4 } & Pembina Utama & IV/e & - \\
\hline
\end{tabular}

Jumlah minimum angka kredit pada kegiatan PKB untuk memenuhi persyaratan kenaikan pangkat/jabatan guru setiap jenjang sebagai berikut.

Tabel 3. Jumlah Angka Kredit Pada Kegiatan PKB yang Diperlukan untuk Memenuhi Persyaratan Kenaikan Pangkat

\begin{tabular}{|l|l|l|l|}
\hline \multirow{2}{*}{ Dari Jabatan } & \multicolumn{1}{|c|}{ Ke Jabatan } & \multicolumn{2}{c|}{$\begin{array}{c}\text { Jumlah Angka Kredit Minimum dari } \\
\text { Subunsur }\end{array}$} \\
\cline { 3 - 5 } & & \multicolumn{1}{c|}{$\begin{array}{c}\text { Pengembangan } \\
\text { Diri }\end{array}$} & $\begin{array}{c}\text { Publikasi Ilmiah } \\
\text { dan/atau Karya } \\
\text { Inovatif }\end{array}$ \\
\hline $\begin{array}{l}\text { Guru Pertama } \\
\text { Golongan III/a }\end{array}$ & $\begin{array}{l}\text { Guru Pertama } \\
\text { Golongan III/b }\end{array}$ & 3 (tiga) & - \\
\hline $\begin{array}{l}\text { Guru Pertama } \\
\text { Golongan III/b }\end{array}$ & $\begin{array}{l}\text { Guru Muda } \\
\text { Golongan III/c }\end{array}$ & 3 (tiga) & 4 (empat) \\
\hline $\begin{array}{l}\text { Guru Muda } \\
\text { Golongan III/c }\end{array}$ & $\begin{array}{l}\text { Guru Muda } \\
\text { Golongan III/d }\end{array}$ & 3 (tiga) & 6 (enam) \\
\hline $\begin{array}{l}\text { Guru Muda } \\
\text { Golongan III/d }\end{array}$ & $\begin{array}{l}\text { Guru Madya } \\
\text { Golongan IV/a }\end{array}$ & 4 (empat) & 8 (delapan) \\
\hline $\begin{array}{l}\text { Guru Madya } \\
\text { Golongan IV/a }\end{array}$ & $\begin{array}{l}\text { Guru Madya } \\
\text { Golongan IV/b }\end{array}$ & 4 (empat) & 12 (duabelas) \\
\hline $\begin{array}{l}\text { Guru Madya } \\
\text { Golongan IV/b }\end{array}$ & $\begin{array}{l}\text { Guru Madya } \\
\text { Golongan IV/c }\end{array}$ & 4 (empat) & 12 (duabelas) \\
\hline $\begin{array}{l}\text { Guru madya } \\
\text { Golongan IV/c }\end{array}$ & $\begin{array}{l}\text { Guru Utama } \\
\text { Golongan IV/d }\end{array}$ & 5 (lima) & 14 (empat belas) \\
\hline $\begin{array}{l}\text { Guru Utama } \\
\text { Golongan IV/d }\end{array}$ & $\begin{array}{l}\text { Guru Utama } \\
\text { Golongan IV/e }\end{array}$ & 5 (Lima) & 20 duapuluh \\
\hline
\end{tabular}

Adapun ragam jenis publikasi ilmiah/karya inovatif untuk setiap jenjang jabatan sebagai berikut.

Tabel 4 . Ragam Jenis PI/KI untuk Setiap Jenjang Jabatan 


\begin{tabular}{|c|c|c|c|}
\hline Dari Jabatan & Ke Jabatan & $\begin{array}{c}\text { Jumlah Angka } \\
\text { Kredit dari sub- } \\
\text { unsur PI/KI }\end{array}$ & $\begin{array}{c}\text { Macam Publikasi } \\
\text { Ilmiah/Karya Inovatif } \\
\text { yang Wajib Ada }\end{array}$ \\
\hline $\begin{array}{l}\text { Guru Pertama } \\
\text { Golongan III/a }\end{array}$ & $\begin{array}{l}\text { Guru Pertama } \\
\text { Golongan III/b }\end{array}$ & - & $\begin{array}{l}\text { Bebas pada jenis } \\
\text { karya PI/KI }\end{array}$ \\
\hline $\begin{array}{l}\text { Guru Pertama } \\
\text { Golongan III/b }\end{array}$ & $\begin{array}{l}\text { Guru Muda } \\
\text { Golongan III/c }\end{array}$ & 4 (empat) & $\begin{array}{l}\text { Bebas pada jenis } \\
\text { karya PI/KI }\end{array}$ \\
\hline $\begin{array}{l}\text { Guru Muda } \\
\text { Golongan III/c }\end{array}$ & $\begin{array}{l}\text { Guru Muda } \\
\text { Golongan III/d }\end{array}$ & 6 (enam) & $\begin{array}{l}\text { Bebas pada jenis } \\
\text { karya PI/KI }\end{array}$ \\
\hline $\begin{array}{l}\text { Guru Muda } \\
\text { Golongan III/d }\end{array}$ & $\begin{array}{l}\text { Guru Madya } \\
\text { Golongan IV/a }\end{array}$ & 8 (delapan) & $\begin{array}{l}\text { Minimal terdapat } \\
\text { 1(satu) laporan hasil } \\
\text { penelitian }\end{array}$ \\
\hline $\begin{array}{l}\text { Guru Madya } \\
\text { Golongan IV/a }\end{array}$ & $\begin{array}{l}\text { Guru Madya } \\
\text { Golongan IV/b }\end{array}$ & 12 (duabelas) & $\begin{array}{l}\text { Minimal terdapat } \\
\text { 1(satu) laporan hasil } \\
\text { penelitian dan artikel } \\
\text { yang dimuat di jurnal } \\
\text { yang ber-ISSN }\end{array}$ \\
\hline $\begin{array}{l}\text { Guru Madya } \\
\text { Golongan IV/b }\end{array}$ & $\begin{array}{l}\text { Guru Madya } \\
\text { Golongan IV/c }\end{array}$ & 12 (duabelas) & $\begin{array}{l}\text { Minimal terdapat } \\
\text { (satu) laporan hasil } \\
\text { penelitian dan artikel } \\
\text { yang dimuat di jurnal } \\
\text { yang ber-ISSN }\end{array}$ \\
\hline $\begin{array}{l}\text { Guru Madya } \\
\text { Golongan IV/c }\end{array}$ & $\begin{array}{l}\text { Guru Utama } \\
\text { Golongan IV/d }\end{array}$ & 14 (empat belas) & $\begin{array}{l}\text { Minimal terdapat } \\
\text { 1(satu) laporan hasil } \\
\text { penelitian dan artikel } \\
\text { yang dimuat di jurnal } \\
\text { yang ber-ISSN dan } \\
\text { 1(satu) buku pelajaran } \\
\text { atau buku pendidikan } \\
\text { yang ber-ISBN }\end{array}$ \\
\hline $\begin{array}{l}\text { Guru Utama } \\
\text { Golongan IV/d }\end{array}$ & $\begin{array}{l}\text { Guru Utama } \\
\text { Golongan IV/e }\end{array}$ & 20 (duapuluh) & $\begin{array}{l}\text { Minimal terdapat } \\
\text { 1(satu) laporan hasil } \\
\text { penelitian dan artikel } \\
\text { yang dimuat di jurnal } \\
\text { yang ber-ISSN dan } \\
\text { 1(satu) buku pelajaran } \\
\text { atau buku pendidikan } \\
\text { yang ber-ISBN }\end{array}$ \\
\hline
\end{tabular}


Demi lebih jelasnya, dapat dikemukakan ilustrasi sebagai berikut. Bagi guru yang dalam pangkat/jabatan III/c, untuk bisa naik mencapai pangkat/jabatan III/d harus mencapai angka kredit kumulatif(AKK) 100. AKK itu dipersyaratkan berasal dari unsur utama Pengembangan Keprofesian Berkelanjutan, paling sedikit 6 angka kredit dari sub-unsur PI dan atau KI, dan paling sedikit 3 angka kredit dari sub-unsur PD. Meskipun angka kredit yang dicapai telah mencukupi atau bahkan melampaui AKK, apabila angka kredit untuk unsur PKB tidak tercapai, maka tidak dapat dipertimbangkan untuk mengajukan kenaikan pangkat/jabatan. Sehingga, guru yang menginginkan untuk segera mendapatkan kenaikan pangkat/jabatan, mau tidak mau harus memenuhiangka kredit dari unsur PKB, baik dari sub-unsur PI dan/atau KI maupun PD. Target 6 angka kredit dari unsur PKB tersebut, dari sub-unsur PI dan/atau KI maupun PD. Bagaimanapun, persyaratan PKB bagi guru teramat membawa manfaat langsung bagi peserta didik maupun bagi guru/pendidik itu sendiri.

Perubahan yang mendasar dari Permenpan dan RB Nomor 16 Tahun 2009itu, bahwa pada unsur pembelajaran/bimbingan dan tugas tertentu harus ada bukti satuan hasil berupa laporan penilaian kinerja. Demikian juga pada unsur PKB harus ada bukti fisik berupa surat tugas, laporan deskripsi hasil pelatihan, dan sertifikat, serta angka kredit yang diperhitungkan dalam bentuk satu paket. Jumlah AKK diperoleh dari unsur utama (pendidikan, PK Guru, PKB)=90\% dan unsur penunjang $=10 \%$ (Wibowo, 2012: 12-13).

\section{PI bagi Guru Seni Budaya}

Guru sebagai bagian dari "ilmuwan pendidikan" mempunyai kewajiban untuk meningkatkembangkan potensinya. Seperti yang terkandung dalam sebuah slogan publish or perish,bahwa seorang guru yang tidak mau menulis dan mengemukakan pendapat, ide, atau gagasannya, maka ia akan tersingkir dari dunia akademik, kaumintelektual, kaumterpelajar, ataukaumterdidik. Guru-tak terkecuali guru Seni Budaya--berkewajiban melakukan pemikiranpemikiranilmiahdanpenelitian-penelitian ilmiahdalam rangka mencaritemukan terobosan-terobosan baru demi kemajuan danpengembanganduniapendidikan. 
Hasil pemikirandanpenelitianilmiahdariparaguru tersebut hendaknya juga dipublikasikankepada masyarakatakademik yang lain. Sehingga,pemikiranataupenelitian yang semuladilakukansecara personal inidapat dimanfaatkansecarakomunal, bahkankalaudimungkinkansecara universal. Dan yang pasti,tulisanilmiahpara guru tersebut tidak hanya berhenti dalam bentuk tulisan sebagai pemanis meja atau rak buku saja.

Keengganan menulis pada guru, seringkali hanya karena alasan klise, yakni“belum menemukan masalah" atau "tidak ada masalah". Padahal, sesungguhnya banyak sekali permasalahan di depan mata yang bisa diangkat menjadi sumber penulisan ilmiah. Fenomena-fenomena yang oleh sementara guru dianggap bukan permasalahan, di matapara guru yang aktif, kritis, kreatif, dan inovatif sangat dimungkinkan untuk menjadi problematika yang sangat menarik.

\section{Guru-guruSeni-Budaya}

berpeluangmendapatkansumberpermasalahandaripengalaman pembelajaran yang dilakukan sehari-hari terhadap murid-muridnya. Misalnya, selama ini kebanyakan guru taridalam menyampaikan materi pembelajaran seni tari selalubersandarpadateacher centered, yaknimetode imam, ataumetodeimitasi. Guru-guru tari yang kreatifinovatifdimungkinkanuntukberupayamencaritemukanpendekatan,metode,atautekn ikpembelajaran yang lebihefektifdaripadaitu.Akhirnya, merekamelakukanpenelitianeksperimen yang mencobamelihatperbedaanefektivitasantarametodeimitasidenganmetode SAS ataumetodeImersi, misalnya, yang jelas-jelaslebihbernuansastudent centered.

Masih banyak model pembelajaran yang lebihefektifbisa diterapkanolehpara guru. Guru sebaiknyamau berinovasi denganmenciptakan model-model pembelajaran yang baruataumemberikannilaitambahpada model pembelajaran yang sudahada. Guru hendaknya berupaya mencari strategi-strategi baru, sehinggadidapatkan pengetahuan tentang perubahan (changes) dan 
peningkatan (improvement) sebagai dampak suatu tindakan yang mampu memberdayakan kelompok sasaran.

Peserta didik dapattermotivasi dalam belajar tari, sehingga anggapan bahwa seni-budaya (c.q. seni tari) adalah mata pelajaran yang tidak menarik dan 'mboseni' dapat ditepis. Apalagi untuk materi seni tari kreasi, peserta didik harusnya benar-benar diposisikan sebagai subjek yang aktif. Peserta didik diberi ruang yang cukup agar dapat bereksplorasi sesuai bekal pengetahuan dan kemampuannya, meski tetap tidak terlepas dari bingkai pengawasan, bimbingan, dan arahan dari guru. Pendidikan seni-budaya dapat dilaksanakan dalambingkaieducation through arts, education with arts, dan/ataueducationabout arts.

Kaitannya dengan pelaksanaan kegiatan PKB dalam rangka meningkatkan jenjang pangkat/jabatan guru, banyak kegiatan yang dapat dilakukan oleh guru seni-budaya. Dari unsur PI, guru dapat membuat karya berupa diktat pelajaran, modul, buku pedoman guru, makalah tinjauan ilmiah, dan laporan hasil penelitian(Penelitian Tindakan Kelas). PI tersebut sangat mungkin dilaksanakan oleh guru karena sumber dan permasalahannya bersentuhan langsung dengan guru dalam menjalankantugaspokokdanfungsi (tupoksi)-nya. Sedangkan, dari unsur KI, guru Seni-Budayadapat menyusun karya inovatif sesuai disiplinmasing-masing, yaitu menemukan atau menciptakan karya seni, membuat atau memodifikasi alat pelajaran, alatperaga, alatpraktikum, danseterusnya.

Kriteria untuk sub-unsur menciptakan karya seni dan angka kreditnya sebagai berikut.

Tabel5.KriteriaKaryaSeni, Kategori, dan AK.

\begin{tabular}{|l|c|c|c|}
\hline No. & Kriteria Karya Seni & Kategori & A.K \\
\hline 1. & $\begin{array}{c}\text { Seni Sastra: } \\
\text { - Setiap judul buku novel, naskah } \\
\text { drama/film, atau buku cerita }\end{array}$ & & \\
& bergambar(komik) yang diterbitkan, ber- & & \\
& $\begin{array}{l}\text { ISBN, dan diedarkan secara luas. } \\
\text { Setiap judul buku kumpulan minimal10 }\end{array}$ & & \\
&
\end{tabular}




\begin{tabular}{|c|c|c|c|}
\hline 2. & $\begin{array}{l}\text { cerpen, buku kumpulan minimal } 20 \text { puisi, } \\
\text { atau buku kiumpulan } 10 \text { naskah } \\
\text { aransemen lagu karya seorang yang } \\
\text { diterbitkan, ber-ISBN, dan diedarkan } \\
\text { secara luas. }\end{array}$ & Sederhana & 2 \\
\hline 2. & $\begin{array}{l}\text { Seni Desain Komunikasi Visual: } \\
\text { - Setiap judul film/sinetron/wayang atau } \\
\text { judul lagu company profile berdurasi } 15 \\
\text { menit, diedarkan secara luas dan diakui } \\
\text { oleh masyarakat. } \\
\text { - Setiap minimal } 5 \text { judul lagu } \\
\text { rekaman(kaset,CD/VCD/DVD) yang } \\
\text { diedarkan srcara luas dan diakui oleh } \\
\text { masyarakat. } \\
\text { - Setiap minimal } 5 \text { judul sampul buku } \\
\text { berwarna yang diedarkan secara luas dan } \\
\text { diakui oleh masyarakat. } \\
\text { - Setiap minimal } 5 \text { baliho/poster seni yang } \\
\text { berbeda, ukuran minimal } \\
\text { meter,dipasang ditempat umum dan diakui } \\
\text { oleh masyarakat. } \\
\text { Setiap minimal } 20 \text { poster/pamflet/brosur } \\
\text { seni yang berbeda, ukuran kecil, dicetak } \\
\text { berwarna dan diedarkan secara luas dan } \\
\text { diakui oleh masyarakat. }\end{array}$ & Kompleks & 4 \\
\hline 3. & $\begin{array}{l}\text { Seni Busana: } \\
\text { - Setiap minimal } 10 \text { kreasi busana yang } \\
\text { berbeda, diperagakan, dan diakui oleh } \\
\text { masyarakat. }\end{array}$ & Kompleks & 4 \\
\hline 4. & $\begin{array}{l}\text { Seni Rupa: } \\
\text { - Setiap } 5 \text { lukisan/patung/keramik yang } \\
\text { berbeda, dipamerkan dan diakui oleh } \\
\text { masyarakat. } \\
\text { - Setiap } 10 \text { karya seni fotografi yang } \\
\text { berbeda, dipamerkan/dipublikasikan dan } \\
\text { diakui oleh masyarakat. } \\
\text { - Setiap } 10 \text { karya seni ukuran kecil yang } \\
\text { berfungsi sebagai suvenir, diedarkan } \\
\text { secara luas dan diakui oleh masyarakat }\end{array}$ & Kompleks & 4 \\
\hline 5. & $\begin{array}{l}\text { Seni Pertunjukan: } \\
\text { - Setiap pementasan teater/drama, tari, } \\
\text { sendratari, atau ansambel musik dengan } \\
\text { durasi minimal } 1 \text { jam dan diakui oleh }\end{array}$ & Kompleks & 4 \\
\hline
\end{tabular}


\begin{tabular}{|l|l|l|l|}
\hline & masyarakat & \\
\hline
\end{tabular}

Kategori kompleks untuk kriteria karya seni mengacu pada lingkup publikasi/peredaran/pameran/pertunjukan/lomba/pengakuan karya seni pada tingkat provinsi/nasional/internasional. Sedangkan kategori sederhana mengacu pada lingkup publikasi/peredaran/pameran/pertunjukan/lomba/pengakuan karya seni pada tingkat kecamatan/kabupaten/kota.

Sedangkan kriteria dan angka kredit untuk sub-unsur membuat/memodifikasi alat pelajaran, alatperaga, ataualatpraktikum sebagai berikut.

Tabel6.Kegiatan, MacamPublikasi, SatuanHasil, dan AK.

\begin{tabular}{|l|l|c|c|c|}
\hline No. & \multicolumn{1}{|c|}{ Kegiatan } & Macam Publikasi & Satuan Hasil & $\begin{array}{c}\text { Angka } \\
\text { Kredit }\end{array}$ \\
\hline 1 & $\begin{array}{l}\text { Membuat Alat } \\
\text { Pelajaran }\end{array}$ & Kategori Kompleks & Hasil karya & 2 \\
\cline { 3 - 5 } & Kategori Sederhana & Hasil karya & 1 \\
\hline 2 & $\begin{array}{l}\text { Membuat alat } \\
\text { Peraga }\end{array}$ & Kategori Kompleks & Hasil Karya & 2 \\
\cline { 3 - 5 } & Kategori Sederhana & Hasil Karya & 1 \\
\hline 3 & $\begin{array}{l}\text { Membuat alat } \\
\text { Praktikum }\end{array}$ & Kategori Kompleks & Hasil Karya & 2 \\
\cline { 3 - 5 } & Kategori Sederhana & Hasil karya & 1 \\
\hline
\end{tabular}

Kategori kompleks untuk kriteria membuat/memodifikasi alat pembelajaran, alatperaga, ataualatpraktikum tersebut, bahwaalat itubelum pernah ada sebelumnya, adalahlebih baik daripada sebelumnya(lebih mudah digunakan, lebih praktis, lebih efisien, dan seterusnya), tingkat modifikasi tinggi. Kategori sederhana diterapkanapabila alat tersebut sudah pernah ada sebelumnya, sama baiknya daripada yang adasebelumnya, dan tingkat modifikasinya rendah.

\section{Inovasi dalam Pembelajaran Seni-Budaya}


Guru merupakan komponen pokokdalam menentukan keberhasilan pembelajaran siswa, tanpa mengesampingkan peran faktor lain, sepertimurid, kurikulum, media pembelajaran, sarana-prasarana, maupun lingkungan sekolah. Guru memegang peran utama dalam pembangunan pendidikan menuju tercapainya tujuan pendidikan nasional. Berbagai upaya yang dilakukan untuk meningkatkan kualitas pendidikan terkaiteratdenganpeningkatan kualitas (dan kesejahteraan) guru.

Kompetensi guru sebagai agen perubahandalampembelajaran harus diupayakan secara terus-menerus. Guru yang memilikikompetensiprofesional merupakan kunci utama bagikeberhasilan program pembelajaran. Ketika berada di kelas, guru berhak melakukankreasidaninovasi apa saja untuk keberhasilan pembelajaran. Sudahsaatnya guru untuk bertindakprofesional dan efektif di kelasnya masing-masing ketika ia harus melakukan proses pembelajaran (Suyanto dalam Wibowo, 2012: 17).

Kemampuan profesional menurut Alma (dalam Wibowo, 2012: 118) adalah kemampuan penguasaan materi pelajaran secara luas dan mendalam, serta metode dan teknik mengajar yang sesuai yang dipahami oleh murid, mudah ditangkap, tidak menimbulkan kesulitan dan keraguan. Kemampuan profesional guru tersebut juga ditunjukkan dengan kemampuan guru dalam mengembangkan materi studi yang diajarkan dalam bentuk penelitian dan secara nyata menghasilkan karya-karya produktif, seperti penulisan bahan ajar, termasuk menulis buku yang berkaitan dengan materi yang diajarkan.

Pembelajaran seni budaya yang masuk pada kelompok mata pelajaran estetika yang dimaksudkan untuk meningkatkan sensitivitas, kemampuan mengekspresikan dan kemampuan mengapresiasi keindahan dan harmoni mencakup apresiasi dan ekspresi, baik dalam kehidupan individual, sehingga mampu menikmati dan mensyukuri hidup, maupun dalam kehidupan kemasyarakatan, sehingga mampu menciptakan kebersamaan yang harmonis(Sumaryadi, 2013: 20). 
Inovasi dalam pembelajaran seni dapat diartikan sebagai ide, konsep, dan strategi baru dalam pembelajaran seni yang lebih bermanfaat untuk pengembangan pembelajaranataupendidikan seni tersebut.Misi pemberdayaan, dalam halini, adalahmemberdayakan guru dan sekaligus memberdayakansiswa. Gurudiberdayakan dari sudut pengembangan profesionalitasnya, siswamendapatkan manfaat dari upaya guru karena mendapatkan pelayanan yang lebih baik, sebagai dampak dari meningkatnya kualitas pembelajaran.

\section{Di Balik Sertifikasi Guru}

Tujuan sertifikasi adalah menentukan kelayakan guru dalam melaksanakan tugas sebagai agen pembelajaran dan mewujudkan tujuan pendidikan nasional, meningkatkan proses dan mutu hasil pendidikan, meningkatkan martabat guru, dan meningkatkan profesionalisme guru (Wibowo, 2012: 34). Jadi, bukan berfokus pada peningkatan pendapatan setiap guru yang telah memenuhi syarat tertentu.

Peningkatan jumlah penghasilan guru bukan dimaksudkan guru juga meningkatdalam kreativitas konsumtifnya, tetapi perlu meningkatkan tanggungjawab sesuai tupoksinya. Seiring perkembangan zaman dan berjalannya waktu, memang tidak dapat dipungkiri bahwa kebutuhan dan keinginan manusia siapapun, tak terkecuali guru, juga akan berkembang. Hanya, faktor pengendalian diri dan skala prioritassemestinyadapat menentukan arahnya. Sindiran terhadap perilaku guru banyak bermunculan, khususnyauntuk mereka yang telah kelirudalammemanfaatkan tunjangan sertifikasi, misalnyasindirantentangperilaku sejumlah guru yang menggunakan tunjangan sertifikasi untuk belanja atau kredit yang cenderungkonsumtif (CeramahBupatiKaranganyar,Yuliatmono,pada 8 Agustus 2015 di Gedung Wanita Karanganyar). Tunjangan sertifikasi itu diberikan dengan harapan dapatmembangunkedisiplinan dan motivasi guru untuk meningkatkan profesionalitas guru, bukan hanya untuk mendapatkan barangbarang konsumtif.Indikator profesional dalamhalinidiantaranya mencintai pekerjaan, disiplin, dan kreatif. 
Tuntutan beban mengajar yang dipersyaratkan dalam pengajuan pencairan tunjangan profesi minimal 24 jam/minggu, tampak banyak menimbulkan permasalahan. Bagi guru yang beban mengajarnya kurang dari 24 jam,otomatis tidak akan bisa mengajukan berkas pencairan tunjangan profesi. Keadaan seperti itu tidak akan berhenti sampai di situ. Demi mendapatkan tunjangan sertifikasi, seorangguru akan berupaya mencari tambahan jam mengajar di sekolah lain yang sederajatatau sejenjang, bahkan lintas jenjang. Kalau sudah demikian halnya, bisa dibayangkan bagaimana kualitas pembelajaran yang menjadi tanggungjawab guru itu. Guru itu mesti mengajar sambil berkejaran dalam membagi waktu. Belum lagi munculnya kekhawatiran apakah guru tersebut masih memiliki waktu, tenaga, dan pikiran untuk mempersiapkan segala macam administrasi pada lebih dari satu sekolah tersebut. Pertanyaan akankah tercapai tujuan pembelajarannya dan dapat meningkatkah mutu pembelajaran yang dilakukan oleh guru itu terasa wajar untuk dipertanyakan oleh publik.

Permasalahan sosial, di sisi lain, juga akan mengemuka. Permasalahan ini terjadi manakala di suatu sekolah terdapat lebih dari 1 guru untuk 1 mata pelajaran yang sama, dengan status guru sama-sama memiliki sertifikat pendidik profesional. Sesuai kebijakan, pastilah guru yang memenuhi kriteria yang akan dipenuhi jam mengajarnya terlebih dahulu. Di sinilah dapat muncul 'rasa cemburu' dan 'rasa telah dirugikan' dari yang satu oleh yang lainnya. Hal itu jika tidak segera diselesaikan secara arif, tentu akan mempengaruhi kondusivitas lingkungan sekolah yang bersangkutan, yang berakibat akan mengorbankan kepentingan anak didik.

Ekuivalensi beban tugas tambahan terhadap pemenuhan jam mengajar yang diatur melalui Permendikbud RI Nomor 4 Tahun 2014 ternyata juga belum bisa menuntaskan permasalahan yang ada. Secara adiministratif pemenuhan jam mengajar mungkin bisa teratasi, tetapi penunjukan personalnya sering tidak tepat dalamkompetensinya. Sebagai contoh, penunjukan seseorang guru untukmendudukijabatanWakil Kepala Sekolah (Wakasek), dilakukan bukan 
berdasarkan kompetensi profesionalnya atau integritas dan kapabilitasnya, melainkan lebih karena rasa kemanusiaan demi jumlah jamnya terpenuhi.

Denganalasan guruitu beban mengajarnya baru 12 jam, padahal guru itusudah bersertifikat pendidik profesional, maka demi mendapatkan tunjangan profesi,orang itu diberi tugas tambahan menduduki jabatanWakasek itu. Masalah kemudianyang munculadalahketika orang itutidakmemilikikompetensi sebagai Wakasek. Sementara, kedudukan, peran, dan fungsi seorang Wakasek adalah koordinator berbagai kepentingan sekolah, berada langsung di bawah kedudukan Kepala Sekolah. Eksistensi Wakasek, betapapun, teramat penting dalam menjaga eksistensi sekolah. Hal itu tentunya tidak bias dan tidak boleh digunakan untuk main-main. Bisa dibayangkan jika secara terinci komponen kompetensi tugas tambahan sebagai Wakasek adalah: kepribadian dan sosial, kepemimpinan, pengembangan Sekolah/Madrasah, kewirausahaan, dan bidang tugas.

Ketentuan sertifikasi atas beban jam mengajar guru tampaknya sederhana, tetapi banyak menimbulkan permasalahan yang berdampak mengaburkan tugas dan tanggungjawab guru. Jangankan untuk melaksanakan kegiatan PKB, untuk melaksanakan tugas sesuai tupoksinya saja boleh jadi tidak akan maksimal.

\section{PENUTUP}

Guru merupakan komponen penentu keberhasilan siswa dalam pembelajaran, makapeningkatan kualitas guru yang didukung peningkatan kesejahteraan sangat diperlukan. Dengan catatan, bahwa peningkatan kualitas dan peningkatankesejahteraan guru harus diupayakan dapat berjalan beriringan, khususnya dalam hal ini melalui pelaksanaan kegiatan PKB.

Guru Seni-Budaya sebagai pelaku atau agen dalam pendidikan atau pembelajaran harus selalu berupaya meningkatkan dan mengembangkan potensi dan kompetensinya agar dapat ambil bagian dalam mewujudkan tercapainyatujuan pendidikan dan pembangunan bangsa. Anggapan bahwa mata pelajaran SeniBudaya adalah mata pelajaran sampingan, tidak penting, karena tidak berkontribusi dalam keberhasilan Ujian Nasional, mau tidak mau harus 
diluruskan. Setiap mata pelajaran mempunyai fungsi dan kegunaan masingmasing dalam rangka membentuk manusia seutuhnya, dalam rangka menciptakan situasi sadar budaya, yang pada gilirannya dalam membangun ketahanan budaya yang tangguh pada siswa.

Demikian halnya, terkait dengan tunjangan kesejahteraan guru, pihak atasan guru mesti mampu membuat kebijakan yang arif. Pemenuhan beban/jam mengajar guru, misalnya, disesuaikan dengan ketentuan dan kriteria yang telah ditetapkan. Termasuk pendelegasian tugas tambahan bagi seorang guru hendaknya lebih mengutamakan faktor kelayakan secara kompetensi.

\section{DAFTAR PUSTAKA}

Alamsyah, Munjid Nur. 2015. "Menyusun Karya Tulis Ilmiah dengan Mudah Karya Tulis Bisa!".Makalah disampaikan pada Lokakarya Penulisan Artikel WUNY bagi para Guru. Yogyakarta: LPPMP UNY.

Menteri PAN dan RB. 2009. Peraturan Menteri PendayagunaanAparatur Negara dan Reformasi Birokrasi Nomor 16 Tahun 2009 tentang JabatanFungsional Guru dan Angka Kreditnya. Jakarta: Kemenpan dan RB RepublikIndonesia.

Menteri Pendidikan Nasional. 2011. Pedoman Kegiatan Pengembangan Keprofesian Berkelanjutan (PKB) dan Angka Kreditnya. Jakarta: Direktorat Jenderal Peningkatan Mutu Pendidik dan Tenaga Kependidikan.

Peraturan Pemerintah RI Nomor 19Tahun2005. Tentang Standar Nasional Pendidikan. Jakarta.

Permendikbud RI Nomor 4 Tahun 2015. Tentang Ekuivalensi Kegiatan Pembelajaran/Pembimbingan bagi Guru yang Bertugas pada SMP/SMA/SMK yang Melaksanakan Kurikulum 2013. Jakarta: Kemdikbud.

Sumaryadi. 2013. "Dari Jurdik Sendratasik ke Dik Senibud”.Prosiding Seminar Nasional 'Inovasi Pembelajaran Seni'. Jakarta: Universitas Negeri Jakarta. 
Undang-Undang RI Nomor 20Tahun 2003. Tentang Sistem Pendidikan Nasional. Jakarta.

Undang-Undang RI Nomor 14Tahun 2005. Tentang Guru dan Dosen. Jakarta.

Wibowo,Agus \& Hamrin.2012. Menjadi Guru Berkarakter (Strategi Membangun Kompetensi \& Karakter Guru). Yogyakarta: Pustaka Pelajar. 